\section{Two Hypospadias Cases in a Family with Translocation Involving Chromosomes X and 21}

DOI: 10.1515/rrlm-2015-0018

\section{To the Editor:}

Hypospadias is defined as an abnormally placed urethral opening because of the incomplete development of the penis between 8 and 14 weeks of gestational age. It is a commonly identified congenital anomaly, occurring in approximately 3 individuals in 1000 live male births in European countries, with small variations between different ethnicities or races [1].

The etiology of hypospadias is not clear but is believed to be multifactorial with several genes acting in combination with environmental factors. The presence of both hypospadias alongside cryptorchidism or undescended testes in the same individual warrants consideration for a disorder of sexual development (DSD) and evaluation to rule out congenital adrenal hyperplasia. Subsequently routine karyotyping of all individuals should also be recommended. The incidence of chromosomal anomalies is higher when cryptorchidism is associated with hypospadias compared with patients with only cryptorchidism or hypospadias [2].

In our Department we had the opportunity to observe a translocation between chromosomes X and 21 in two related children with 46,XY DSD. Clinical examination, cytogenetic analysis and hormonal analysis were recorded in our index case, a boy with DSD identified at birth and his uncle with hypospadias. Informed consent was obtained from the children's parents involved in the study, regarding the genetic investigation.
The index case is the first child of a consanguineous couple, with no significant medical history. He was born after a normal vaginal delivery, with a birth weight of $3100 \mathrm{~g}$ and a birth height of $50 \mathrm{~cm}$.

Physical examination revealed posterior (proximal) peno-scrotal hypospadias (urethral meatus located where the base of the penis and the scrotum meet), micropenis and bifid scrotum without gonads in the scrotum. No other congenital abnormalities or dysmorphic features were noticed.

At 2 weeks old, with no medication being administered, laboratory results revealed - LH: 2.6 $\mathrm{mUI} / \mathrm{ml}$, FSH: $0.84 \mathrm{mUI} / \mathrm{ml}$, testosterone: 4.38 $\mathrm{nmol} / \mathrm{l}$ and $17-\mathrm{OH}$ progesterone: $4.84 \mathrm{nmol} / \mathrm{L}$.

Chromosome analysis identified 46,Y,t(X;21) (p10;q10). Peripheral blood samples collected on sodium heparin were used for cytogenetic analysis, short-term cultures (72 hours at $37^{\circ}$ ) on ready-to-use complete medium being performed. Cultures were subsequently exposed to Colcemid (KaryoMAX® Colcemid solution) and treated with a hypotonic solution $(0.075 \mathrm{M}$ $\mathrm{KCl}$ solution), fixed with a fresh standard fixator solution (a mixture of absolute methanol and glacial acetic acid). The resulting cell suspension was spread on cold and wet microscope slides which were exposed to trypsin treatment for conventional Giemsa banding (GTG banding) technique (450-550 bands). For each investigated case twenty metaphases were analyzed using a BX51 Olympus microscope and an automated image analysis system (Cytovision from Applied Imaging). We used the recommendations of the International System for Human Cytogenetic Nomenclature (ISCN 2009) to describe chromosomal abnormalities identified by conventional cytogenetic analysis [3]. 
When our index case reached 3 months of age a hCG (human chorionic gonadotropin) stimulation test was performed $\left(1500 \mathrm{UI} / \mathrm{m}^{2}\right.$, day 1 and 2) and the basal results were FSH: $1.6 \mathrm{mUI} / \mathrm{ml}$, LH: $3.7 \mathrm{mUI} / \mathrm{ml}$, testosterone: $2.74 \mathrm{nmol} / \mathrm{L}$. On day 3 , testosterone was $11.41 \mathrm{nmol} / \mathrm{L}$ and on day 6 testosterone was $10.82 \mathrm{nmol} / \mathrm{L}$. At 12 months old orchidopexy and surgical correction of the hypospadias were performed.

The second case we present is the ten yearold uncle of our proband. He was at his first endocrine evaluation and presented no significant medical history. Physical examination was normal except middle hypospadias, proximal penile type. His weight was $38 \mathrm{~kg}$, height $149 \mathrm{~cm}$, presented Tanner stage I for pubic hair and he had a bilateral testicular volume of $6 \mathrm{ml}$.

His hormonal levels were: LH: $2.04 \mathrm{mUI} /$ $\mathrm{ml}, \mathrm{FSH}: 3.39 \mathrm{mUI} / \mathrm{ml}$ and testosterone: 2.168 $\mathrm{nmol} / \mathrm{L}$. During the following weeks corrective surgery was carried out.

Chromosome analysis (figure 1A) revealed the same chromosomal rearrangement $46, \mathrm{Y}, \mathrm{t}(\mathrm{X} ; 21)(\mathrm{p} 10 ; \mathrm{q} 10)$ as in the case of his nephew, that we have previously described.

The mother of the index case (which is also the sister of the second case) showed the same chromosomal rearrangement 46,X,t $(\mathrm{X} ; 21)$ (p10;q10) when cytogenetic analysis was performed, but no endocrine abnormalities or congenital malformations were found. The genealogical tree of this family is presented in figure $1 \mathrm{~B}$.

We established the presence of an X-autosomal translocation in the investigated family. We offered genetic advice to the family and asked them to discuss with relatives of the propositus' mother, but they declined our recommendation so no other members of this family were consulted or genetically tested. The mother of the index case being a balanced $\mathrm{X}$-autosome translocation carrier had a great risk of having abnormal offspring due to an unbalanced chromosomal con- stitution. In the case of fertile female heterozygotes the risk is estimated in the $20-40 \%$ range [4]. In case of another pregnancy, prenatal cytogenetical analysis was also advised for the mother of the index case.

Chromosomal abnormalities have been shown to occur with a relatively high incidence in humans with isolated hypospadias $(5.6 \%$ to $7 \%$ ) [1]. Individuals with cryptorchidism and hypospadias are even more likely to have abnormal karyotypes, although large variations in incidence appear in literature (16\%-64\%) [5].

Meatal location of the hypospadias also appears to be an important physical examination determinant in patients with concomitant cryptorchidism. Cox et al. [5] found no sex-chromosome abnormalities in distal hypospadias and cryptorchidism, whereas $16 \%$ of patients with proximal hypospadias and cryptorchidism had an abnormal karyotype. High rates of abnormal karyotypes have been indicated for penoscrotal and more proximal meatal locations (considered the severe forms of hypospadias).

From our knowledge this is the first familial translocation involving $\mathrm{X}$ and 21 chromosomes associated to hypospadias. We have found in literature several translocations described in patients with genitourinary malformations. Kilic et al. [6] described a severe hypospadias associated with robertsonian translocation, 45,XY,t(13q;14q) in a boy with no endocrine abnormalities. His father had the same balanced 1314 robertsonian translocation. In a Mansouri et al. [7] report, a de novo balanced translocation $\mathrm{t}(6 ; 17)(\mathrm{p} 21.31 ; \mathrm{q} 11.2)$ was associated with hypospadias and anorectal malformation.

In both our patients the only complain was the genital malformation, no other dysmorphic features, congenital abnormalities or endocrine dysfunctions being identified. We used hCG stimulation in our index case to maximize androgenic output and the testis response was normal. The proband's uncle started puberty around 10 years 


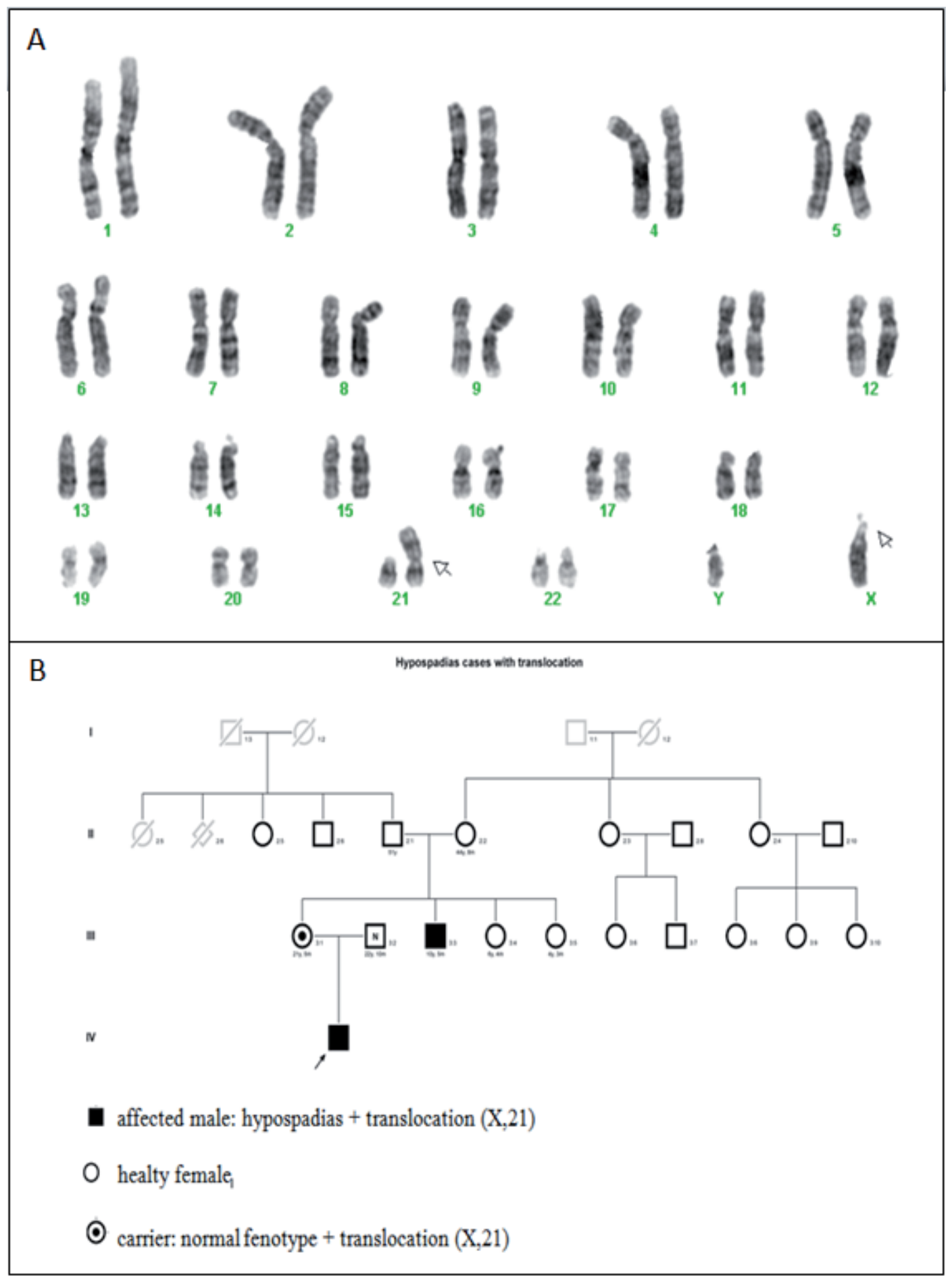

Figure 1. A. Chromosome analysis in both male cases: $46, Y, t(X ; 21)(p 10 ; q 10)$; $B$. The genealogical tree of the family 
of age, another proof of his lack of endocrine dysfunction.

One of the limits of our study derived from the fact that no other members in this family agreed to participate in this study and karyotype has not been performed on other relatives. Despite this limitation, we describe a familial translocation associated with genital malformations expressed only in males. The only logical explanation for this is the involvement of the $\mathrm{X}$ chromosome, in a way similar to the X-linked recessive mode of inheritance. It is possible that a mutation in a recessive gene on the $\mathrm{X}$ chromosome has been disrupted during the rearrangement and this caused the phenotype to be expressed in males who are hemizygous for this mutation. The mother of our proband is a carrier female who has only one copy of the mutation and does not express the phenotype. This supposition may not be accurate because it is well known that a balanced X-autosome translocation can determine a non-random or so called skewed pattern of X-chromosomes inactivation. In these instances, probably because cells containing an imbalance in genetic material can have a survival disadvantage, the derivative $\mathrm{X}$ chromosome typically remains active while the normal $\mathrm{X}$ chromosomes is inactivated [8].

In close vicinity to one of the translocation points (on X chromosome) the androgen receptor (AR) gene (Xq11-12) is localized. The protein codified by this gene functions as a steroid-hormone activated transcription factor [9]. This is the gene we believe has suffered modifications during translocation in our cases because AR plays an important role in penile and urethral development and AR gene mutations (causing partial androgen insensitivity syndrome) have been found to be associated with hypospadias [10].

The main limit of our case report is the lack of a detailed molecular characterization of the rearrangement. Molecular analysis of the breakpoint region with functional consequence studies is required.

In conclusion, it is important to perform a cytogenetic evaluation and in certain situations, specific molecular studies in patients with hypospadias and concomitant cryptorchidism. Most cases of hypospadias have an unknown etiology, which is likely to be a mix of monogenic and multifactorial forms, implicating both genes and environmental factors.

Although no such association has been reported so far, we conclude that DSDs in these two cases are associated with the translocation involving chromosomes $\mathrm{X}$ and 21.

\section{Ionela Pașcanu ${ }^{1,2}$, Claudia Banescu ${ }^{3 *}$, Simona Huțu ${ }^{1}$, Horea Gozar ${ }^{4}$, Radu Neagoe ${ }^{5}$}

\section{Mures County Hospital, Department of}

Endocrinology

2. Department of Endocrinology, University of Medicine and Pharmacy Tg. Mures

3. Department of Genetics, University of Medicine and Pharmacy Tg. Mures

4. Department of Pediatric Surgery, University of Medicine and Pharmacy Tg. Mures

5. $2^{\text {nd }}$ Surgery Clinic, Emergency Mureş County Hospital.

* Corresponding author: Claudia Bănescu, Departament of Medical Genetics, University of Medicine and Pharmacy Tirgu Mures, 38 Gh Marinescu St, 540139, Tirgu Mures, Romania. E-mail: claudia.banescu@gmail.com

\section{Conflicts of interest}

The authors declare that they have no conflict of interest.
Abbreviation list
DSD- disorder of sex development
LH - luteinizing hormone
FSH - follicle-stimulating hormone 
hCG - human chorionic gonadotropin t- translocation

Received: 27th February 2015; Accepted: $28^{\text {th }}$ May 2015; Published: $7^{\text {th }}$ June 2015

\section{References}

1. Shih EM, Graham JM. Review of genetic and environmental factors leading to hypospadias. Eur J Med Genet. 2014 Aug;57(8):453-63. DOI: 10.1016/j. ejmg.2014.03.003

2. Ratan SK, Aggarwal S, Mishra TK, Saxena A, Yadav S, Pandey R, et al. Children with isolated hypospadias have different hormonal profile compared to those with associated anomalies. J Pediatr Endocrinol Metab. 2012;25(1-2):111-9. DOI: 10.1515/jpem.2011.421

3. Shaffer LG, Slovak ML, Campbell LJ. ISCN 2009 An International System for Human Cytogenetic Nomenclature. Recommendations of the International Standing Committee on Human Cytogenetic Nomenclature, Karger, 2009, 59-84.

4. Gardner RJM, Sutherland GR. chromosome abnormalities and genetic counseling. Third edition. Oxford University Press, 2004, 119-121.

5. Cox MJ, Coplen DE, Austin PF. The incidence of Disorders of sexual Differentiation and Chromosomal Abnormalities of Cryptorhidism and Hypospadias Stratified by Meatal Location. J Urol. 2008 Dec;180(6):2649-
52. DOI: $10.1016 /$ j.juro.2008.08.058

6. Kilic N, Balkan E, Saglam H, Yakut T, Dogruyol $\mathrm{H}$. Severe hypospadias associated with robertsonian translocation. Urol Int. 2005;74(4):373-6. DOI: $10.1159 / 000084443$

7. Mansouri MR, Carlsson B, Davey E, Nordenskjöld A, Wester T, Annerén G. Molecular genetic analysis of a de novo balanced translocation $\mathrm{t}(6 ; 17)(\mathrm{p} 21.31 ; \mathrm{q} 11.2)$ associated with hypospadias and anorectal malformation. Hum Genet. 2006 Mar;119(1-2):162-8. DOI: 10.1007/s00439-005-0122-9

8. Cottrell CE, Sommer A, Wenger GD, Bullard S, Busch T, Krahn KN, Lidral AC, Gastier-Foster JM. Atypical $\mathrm{X}$-chromosome inactivation in an $\mathrm{X} ; 1$ translocation patient demonstrating Xq28 functional disomy. Am J Med Genet A. 2009 Mar;149A(3):408-14. DOI: 10.1002/ ajmg.a.32699

9. Hughes IA, Davies JD, Bunch TI, Pasterski V, Mastroyannopoulou K, MacDougall J. Androgen insensitivity syndrome. Lancet. 2012 Oct;380(9851):1419-28. DOI: 10.1016/S0140-6736(12)60071-3

10. van der Zanden LFM, van Rooij IALM, Feitz WFJ, Franke B, Knoers NVAM, Roeleveld N. Aetiology of hypospadias: A systematic review of genes and environment. Hum Reprod Update. 2012 MayJun;18(3):260-83. DOI: 10.1093/humupd/dms002 